Characterization of the $x$-ray sensitivity of a streak camera used at the National Ignition Facility (NIF)

S. F. Khan, J. J. Lee, B. Hatch, G. K. Larsen, N. Izumi, A. G. MacPhee, J. R. Kimbrough, J. P. Holder, M. J. Haugh, Y. P. Opachich, P. M. Bell, D. K. Bradley

September 19, 2013

SPIE Optics + Photonics 2013

San Diego, CA, United States

August 25, 2013 through August 31, 2013 
This document was prepared as an account of work sponsored by an agency of the United States government. Neither the United States government nor Lawrence Livermore National Security, LLC, nor any of their employees makes any warranty, expressed or implied, or assumes any legal liability or responsibility for the accuracy, completeness, or usefulness of any information, apparatus, product, or process disclosed, or represents that its use would not infringe privately owned rights. Reference herein to any specific commercial product, process, or service by trade name, trademark, manufacturer, or otherwise does not necessarily constitute or imply its endorsement, recommendation, or favoring by the United States government or Lawrence Livermore National Security, LLC. The views and opinions of authors expressed herein do not necessarily state or reflect those of the United States government or Lawrence Livermore National Security, LLC, and shall not be used for advertising or product endorsement purposes. 


\title{
Characterization of the $x$-ray sensitivity of a streak camera used at the National Ignition Facility (NIF)
}

\author{
S. F. Khan*a , J. J. Lee ${ }^{\mathrm{b}}$, N. Izumi ${ }^{\mathrm{a}}$, B. Hatch ${ }^{\mathrm{a}}$, G. K. Larsen ${ }^{\mathrm{b}}$, A. G. MacPhee ${ }^{\mathrm{a}}$, J. R. Kimbrough ${ }^{\mathrm{a}}$, \\ J. P. Holder ${ }^{\mathrm{a}}$, M. J. Haugh ${ }^{\mathrm{b}}$, Y. P. Opachich ${ }^{\mathrm{b}}$, P. M. Bell ${ }^{\mathrm{a}}$, D. K. Bradley ${ }^{\mathrm{a}}$ \\ ${ }^{a}$ Lawrence Livermore National Laboratory, 7000 East Ave, Livermore, CA, USA 94550 \\ ${ }^{\mathrm{b}}$ National Security Technologies, LLC, $161 \mathrm{~S}$ Vasco Rd Livermore, CA, USA 94551
}

\begin{abstract}
A neutron hardened x-ray streak camera has been used to report x-ray burn duration and time of peak emission from imploding ICF capsules at the National Ignition Facility with $\sigma<30$ ps. Recent characterization of the instrument using a NIST traceable High Energy X-ray reference source (HEX, National Security Technologies) will enable absolute capsule self-emission x-ray yield measurements $(\mathrm{J} / \mathrm{sr} / \mathrm{keV})$. This manuscript describes the characterization procedure used and preliminary results of the x-ray sensitivity using three different thicknesses of the CsI photocathode.
\end{abstract}

Keywords: inertial confinement fusion (ICF), x-ray diagnostics, HEX lab, NSTec, CsI photocathode, SPIDER

\section{INTRODUCTION}

The National Ignition Facility (NIF) utilizes a suite of complex, state of the art instruments in order to understand the dynamics of Inertial Confinement Fusion (ICF) [1,2] and high energy density experiments [3]. A streak camera, called Streaked Polar Instrumentation for Diagnosing Energetic Radiation (SPIDER), is capable of measuring the temporal flux of emitted x-rays from $7 \mathrm{keV}$ to $40 \mathrm{keV}$ with a temporal resolution and accuracy of $\sigma<20 \mathrm{ps}$ [4]. This instrument has primarily been employed to report the bang time, or time of peak emission, as well as the burn duration from the hot core of imploding DT capsules near peak compression. This measurement aids in validating implosion modeling and to infer implosion velocity [5,6]. Additionally, the relative strength of the signal from SPIDER gives an indication of the quality of the experimental parameters. In order to increase the significance of the measurements from SPIDER, the absolute characterization of the spectral sensitivity was executed at the High Energy X-ray (HEX) lab [7] at the National Security and Technologies, LLC (NSTec) Livermore facility. A determination of the absolute x-ray yield would be useful in several ways: (1) To gauge the relative quality of implosions or back-lighter strength among NIF experiments; (2) as an input parameter into a model that estimates the amount of material mixing that occurs from the capsule outer shell into the fuel layers of the DT capsule [8]; (3) If the x-ray yield is predicted for a particular experiment, then appropriate filtering can be chosen for SPIDER to optimize the dynamic range of the recorded signal. In addition, characterization was performed utilizing three different photocathodes: CsI with a thickness of $0.2 \mu \mathrm{m}, 1.0 \mu \mathrm{m}$ and $10 \mu \mathrm{m}$ in order to determine which one is more efficient in the typical implosion energy range. This paper will describe the procedure, analysis and outcome of this study.

*khan9@1lnl.gov

Paper presented at the SPIE Optics + Photonics 2013 Conference, \#8850-12 


\section{CHARACTERIZATION SETUP}

The HEX Lab x-ray source consists of a commercial $1.8 \mathrm{~kW}$ x-ray tube with a Tungsten anode and a collection of fluorescing foils and paired filters (Figure 1). The resulting x-ray beam primarily consists of the k-shell line emission from the fluorescer material.

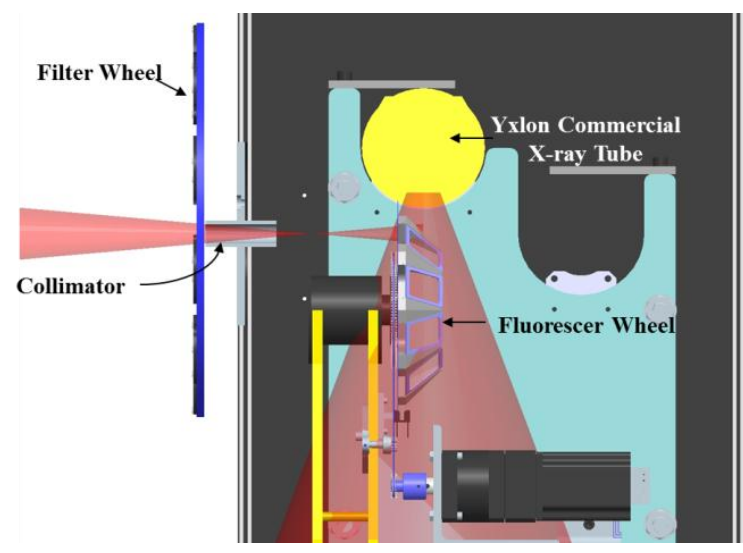

Figure 1. Model of $\mathrm{x}$-ray source: X-rays originating from a commercial $\mathrm{x}$-ray tube (W anode) irradiate elemental foils and create characteristic $\mathrm{x}$-ray fluorescence emission. Another filter that is usually two atomic numbers higher is used to single out the K-alpha lines and further reduce the Bremsstrahlung emission. The path of the $\mathrm{x}$-rays is shown in pink.

The HEX Lab also employs a High Purity Germanium (HPGe) detector [9] manufactured by Canberra to measure the absolute flux of the x-rays produced as a function of energy. The table is setup with rails so that SPIDER and the Canberra detector can easily trade positions in the x-ray beam (Figure 2).

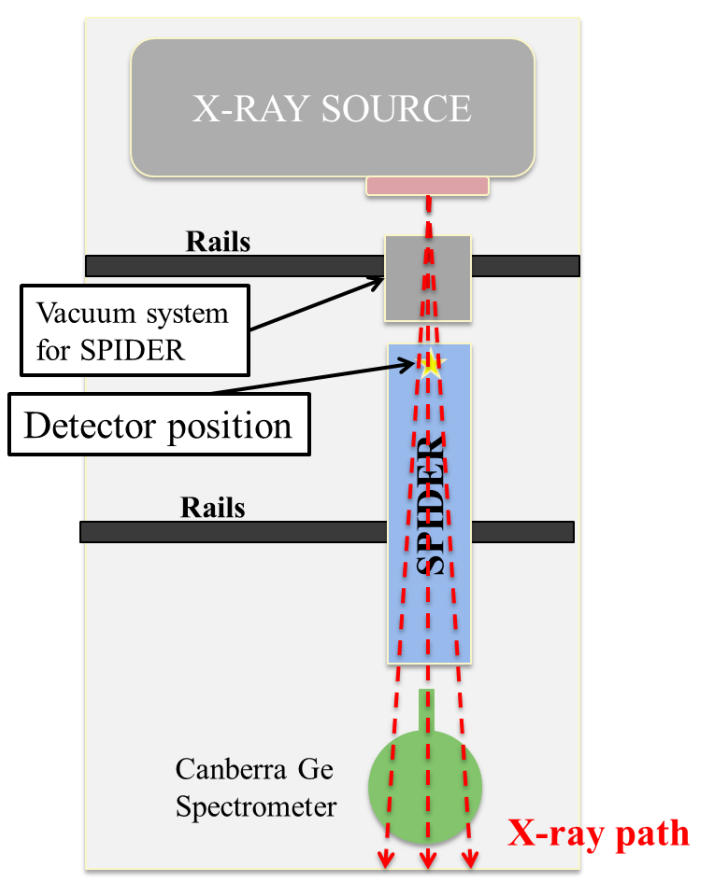

Figure 2. Setup of SPIDER and Canberra Detector is conducive for repetitive measurements at the same positions due to fixed rails. 


\section{CHARACTERIZATION PROCEDURE}

In order to accurately characterize SPIDER, the properties of the $\mathrm{x}$-ray source must be precisely measured. For this effect, the HPGe detector measured the absolute spectral flux of the x-rays and a set of image plates are used to record the spatial profile of the source for each fluorescer and filter combination. Figure 3 shows the spectra from all the fluorescers used in this study as measured by the Canberra HPGe detector. The bremsstrahlung component was successfully attenuated from the recorded signal. The actual exposure time (not counting dead time) used for the detector was 100 seconds for all fluorescers. The $\mathrm{x}$-ray tube voltage and current was increased for the higher $\mathrm{Z}$ materials but kept constant when recorded by each detector. The HPGe detector's spectral efficiency was determined by measuring the response from several NIST calibrated radionuclides. Some of the x-rays that interact with the Ge material produce electrons that escape the detector and are reabsorbed by the Ge with a lower energy [10]. The "escape electron" signal is represented in the correction curve derived from the radionuclides, therefore the escape electron peaks are not counted as part of the flux on the detector. For each fluorescer, the signal after the escape electron peaks is integrated then divided by the spectral efficiency of the detector. The integrated signal is assigned to an energy value determined by taking the center of mass of the signal.

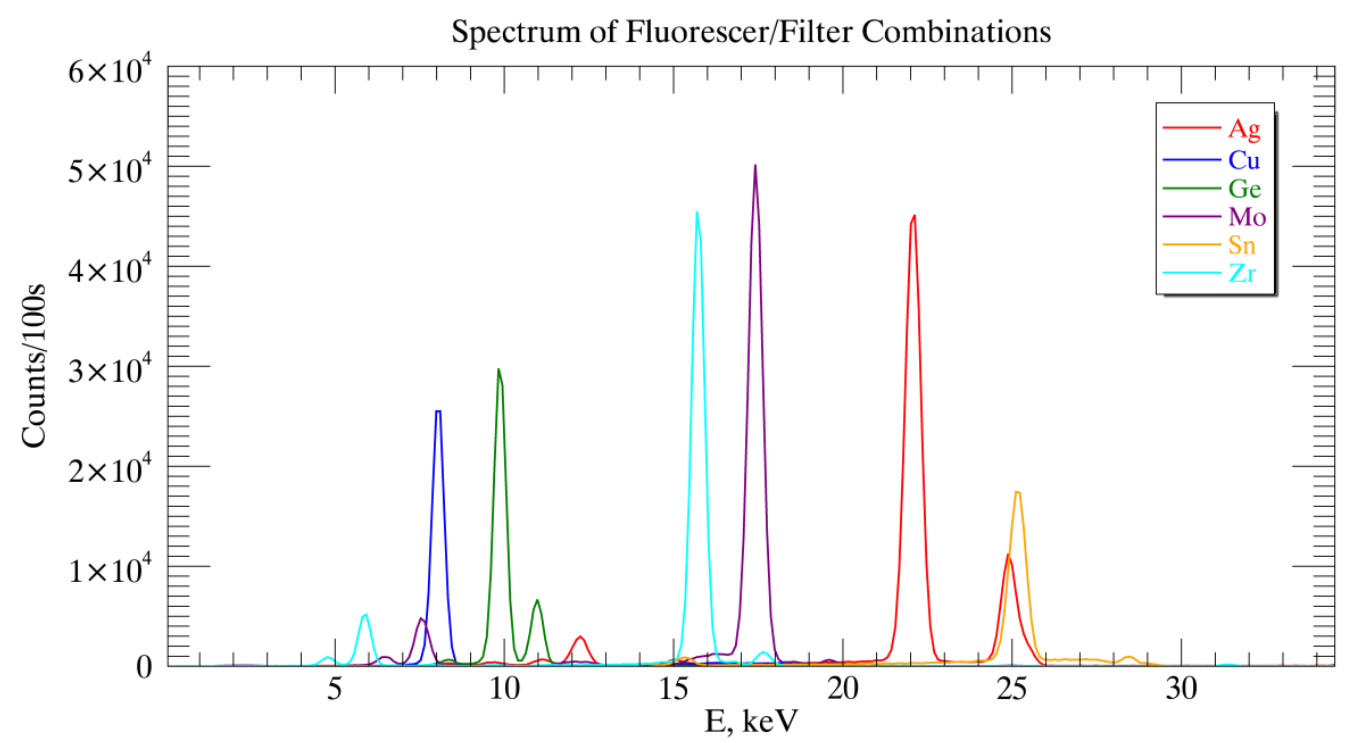

Figure 3. Signal recorded by the Canberra detector for all the fluorescing materials. The Bremsstrahlung component was successfully attenuated. Escape peaks are present but not counted in the flux calculation.

SPIDER and the HPGe detector were placed at the same distance from the x-ray source but were offset by $4.5 \pm 2 \mathrm{~mm}$ horizontally. The offset and the actual size of the aperture on SPIDER and the HPGe detector are used to normalize the effective flux seen by each instrument using the response recorded by images plates, as shown in figure 4 . The uncertainty in the measurement of the location of the photocathode relative to the image plate translates to about a $10 \%$ uncertainty in the flux seen by the instrument. 


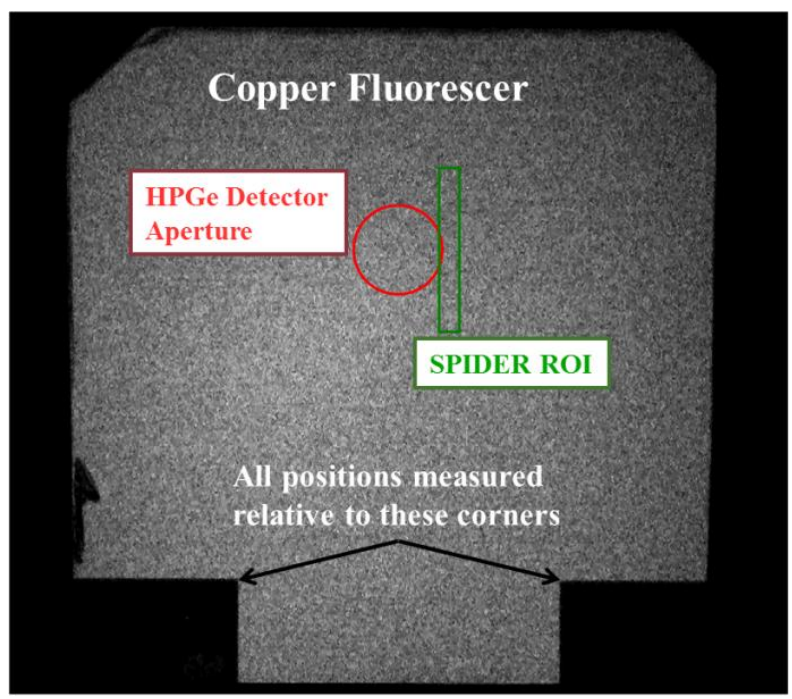

Figure 4. Image plate recording of the spatial variation of the x-ray source. The cutout on the bottom of the image is from the optic holder and serves as fiducial markers for the absolute position.

The actual signal as measured by SPIDER is shown in figure 5. The instrument was used in static mode (not streaked), with an exposure time between 100 to 700 seconds. For two out of the three photocathodes, a slit was not utilized so that an image of the photocathode is observed. A DC bias voltage was applied to the deflector plates (see ref. [4]) in order to separate the signal from the $\mathrm{x}$-rays that pass through the photocathode and interact directly with the micro channel plate. There is a hole in the accelerating mesh to allow a fiber optic cable to deliver a series of temporal fiducial pulses [11] during experiments at NIF. The region of interest (ROI), which was chosen to be well within any artifacts, is the same size as in the image plates. The $10 \mu \mathrm{m}$ thick photocathode has a permanent $1 \mathrm{~mm}$ slit, so its ROI is much thinner.
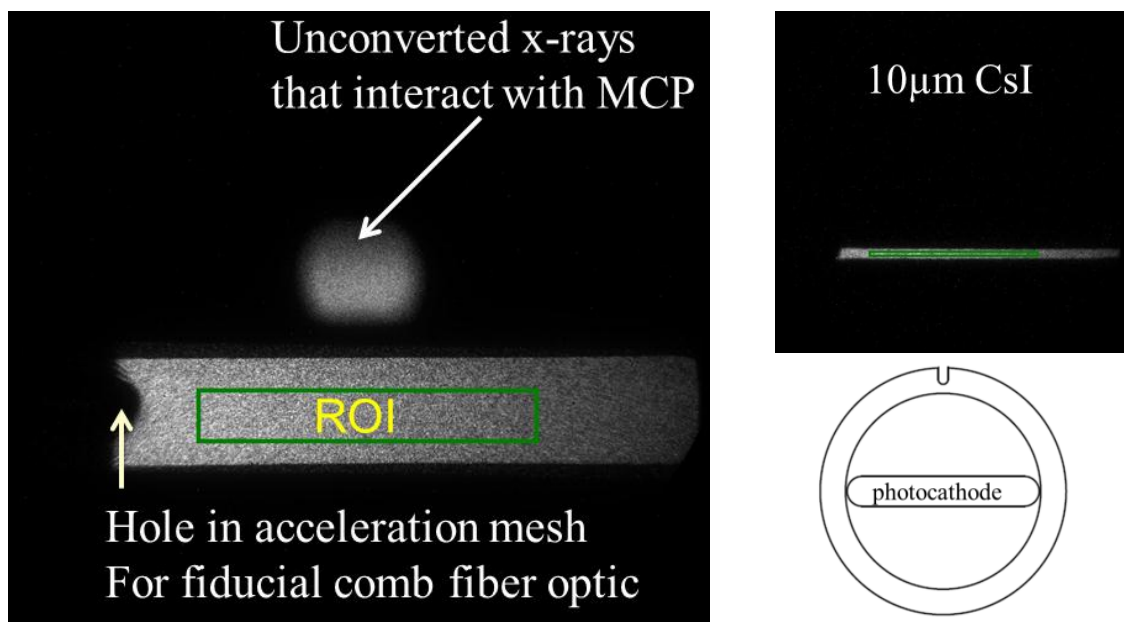

Figure 5. Large image on left represents the image taken by SPIDER for the $0.2 \mu \mathrm{m}$ and $1.0 \mu \mathrm{m}$ thick photocathodes. The upper right image is taken with the $10 \mu \mathrm{m}$ thick photocathode, which had a fixed $100 \mu \mathrm{m}$ slit. The bottom right shows a model of the photocathode as a reference to the size. 


\section{RESULTS}

After taking into consideration all of the conditions of the experiment, the absolute conversion efficiency of SPIDER was calculated and is presented in figure 6. Each point in the plot represents the number of CCD counts per incoming Xray photon for each fluorescing material. A model based on the x-ray absorption of CsI and the escape depth of the secondary photoelectrons is plotted along with the experimental results from all three photocathode thicknesses. The model is scaled to match the $10.2 \mathrm{keV}$ point of the $0.2 \mu \mathrm{m}$ photocathode. The model is fairly close to the experimental results for all three photocathodes, but underestimates the response at the lowest energy. In all cases we find that the response decreases at higher energy as we would expect due to the lower interaction rate of the more energetic x-rays with CsI. However, at energies less than $12 \mathrm{keV}$ the response of the $10 \mu \mathrm{m}$ photocathode is clearly inferior. This is due to the attenuation of the less energetic x-rays before they reach the secondary electron escape depth, the last $25 \mathrm{~nm}$ [12]. The log plot in figure 6 shows a slightly higher response from the $1 \mu \mathrm{m}$ thick photocathode at $>10 \mathrm{keV}$ x-ray energy. This is attributed to the range of the $>10 \mathrm{keV}$ primary photoelectrons produced now being $>0.2 \mu \mathrm{m}$ [13], hence further contributing to the signal for the thicker photocathodes as they form an ionization trail of secondary electrons $[14,15,16]$. Thus, there is an optimum thickness in between that would be best for the relevant energy range for the experiments at NIF. The primary purpose of SPIDER is to look at the emission of $x$-rays from imploding capsules close to bang time; a simulated typical spectrum is shown in figure 7. The signal peaks around $10 \mathrm{keV}$ but has a longer tail towards higher energy. If we take into consideration that some HED experiments at NIF will focus on higher energy emission as well, then it appears that the $1 \mu \mathrm{m}$ thick photocathode would give the best overall results out of the three thicknesses tested.
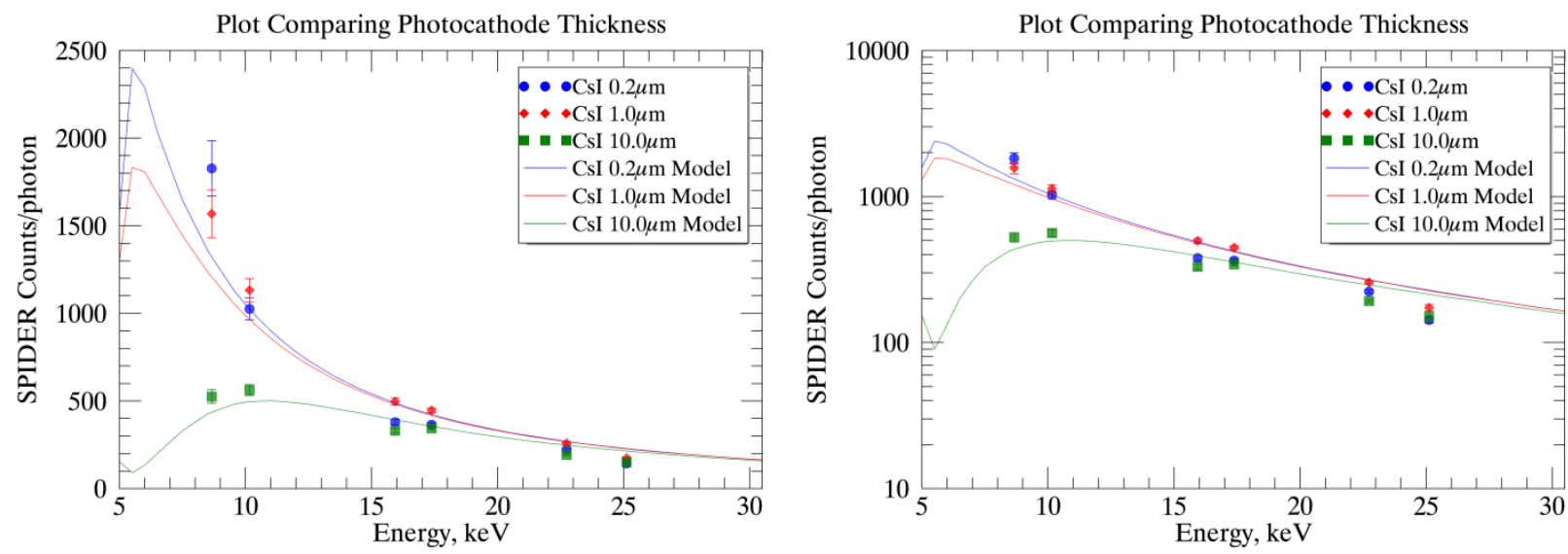

Figure 6. Linear (Left) and Log (Right) plot of the response of SPIDER with three CsI photocathode thicknesses to the number of incoming near-monochromatic x-ray photons at several energies (produced via x-ray fluorescence from $\mathrm{Cu}, \mathrm{Ge}$, $\mathrm{Zr}, \mathrm{Mo}, \mathrm{Ag}$, Sn respectively).

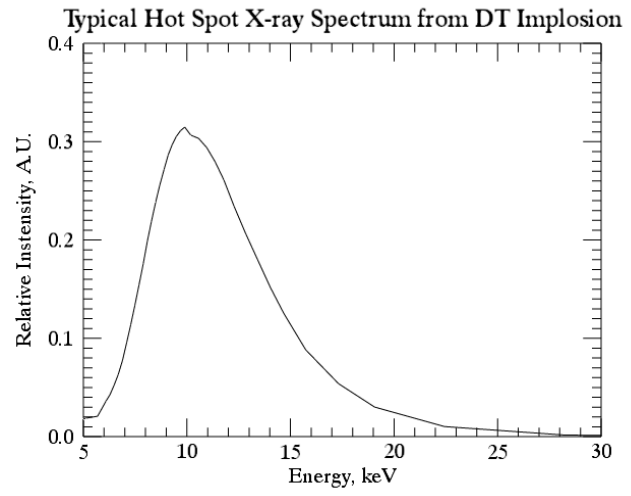

Figure 7. Plot of a simulated hot spot x-ray spectrum from a typical DT implosion. 


\section{CONCLUSION}

The characterization of the response of SPIDER to several $\mathrm{x}$-ray emission lines from $8 \mathrm{keV}$ to $25 \mathrm{keV}$ was performed with three different thicknesses of the CsI photocathode. The response was compared to an HPGe detector, which was calibrated by NIST standard radionuclides, to obtain an absolute conversion efficiency of the entire SPIDER system of CCD counts per incoming $\mathrm{x}$-ray photon. It was found that the response of the instrument degraded with higher energy $\mathrm{x}$ rays. A comparison of the response with the three photocathode thickness shows that the signal with x-rays less than $\sim 9$ $\mathrm{keV}$ is increased with the $0.2 \mu \mathrm{m} \mathrm{CsI}$. The $10 \mu \mathrm{m}$ thick photocathode appears to improve its response relative to the other thicknesses at the highest energy point, so this thickness may be appropriate at $\mathrm{x}$-rays $>30 \mathrm{keV}$. The intermediate thickness of $1.0 \mu \mathrm{m}$ CsI is better suited to record $\mathrm{x}$-rays from $10 \mathrm{keV}$ to $\sim 30 \mathrm{keV}$, which corresponds to the majority of the x-rays that are produced from ICF experiments at NIF. Therefore, the $1.0 \mu \mathrm{m}$ thick CsI photocathode will be used in this SPIDER build, but other thicknesses may be tested in the future to find a more optimal thickness.

\section{ACKNOWLEDGEMENT}

This work was performed under the auspices of the U.S. Department of Energy by Lawrence Livermore National Laboratory under contract DE-AC52-07NA27344 and by National Security Technologies, LLC, under Contract No. DEAC52-06NA25946. IM Release \# LLNL-CONF-643960.

\section{REFERENCES}

[1] Lindl, J. D., Amendt, P., Berger, R. L., Glendinning, S. G., Glenzer, S. H., Haan, S. W., Kauffman, R. L., Landen, O. L., and Suter, L. J., "The physics basis for ignition using indirect-drive targets on the National Ignition Facility," Phys. Plasmas 11, 339 (2004).

[2] Glenzer, S. H., Callahan, D. A., MacKinnon, A. J., Kline, J. L., Grim, G., et al., "Cryogenic thermonuclear fuel implosions on the National Ignition Facility," Phys. Plasmas 19, 056318 (2012).

[3] Moses E. I., Boyd R. N., Remington B. A., Keane C. J., and Al-Ayat R., "The National Ignition Facility: Ushering in a new age for high energy density science," Phys. Plasmas 16, 041006 (2009).

[4] Khan, S. F., et al., "Measuring x-ray burn history with the Streaked Polar Instrumentation for Diagnosing Energetic Radiation (SPIDER) at the National Ignition Facility (NIF)." Proc. SPIE 8505, 05 (2012).

[5] Meezan, N. B., et al., "National Ignition Campaign Hohlraum energetic," Phys. Plasmas 17, 056304 (2010).

[6] Landen, O. L., et al., "Capsule performance optimization in the National Ignition Campaign," Phys. Plasmas 17, 056301 (2010).

[7] Lee, J. J., et al., "Calibrating of x-ray detectors in the 8 to $111 \mathrm{keV}$ energy range and their application to diagnostics on the National Ignition Facility," Proc. SPIE 8505, 08 (2012).

[8] Ma T., et al.,"'Onset of Hydrodynamic Mix in High-Velocity, High Compressed Inertial Confinement Fusion Implosions," Phy. Rev. Lett. 111, 085004 (2013) .

[9] Canberra Industries Product Data Sheet, Ultra_LEGe Detector (GUL), (2013).

[10] Knoll, G. F., [Radiation detection and measurement], John Wiley \& Sons, Hoboken NJ, 330 (2010).

[11] Homoelle, D., et al., "A compact UV timing fiducial system for use with x-ray streak cameras at NIF," Proc. SPIE 8505, 04 (2012).

[12] Henke, B. L., Knauer, J. P., and Premaratne, K., "The characterization of x-ray photocathodes in the 0.1-10-keV photon energy region,” J. Appl. Phys. 52, 3 (1981).

[13] Verma, R. L., "Secondary electron emission of caesium iodide," J. Phys. D: Appl. Phys. 6, 2137 (1973).

[14]Frumkin, I., Breskin, A., Chechik, R., Elkind, V., Notea, A., "Properties of CsI based gaseous secondary emission X-ray imaging detectors," Nucl. Instrum. Methods Phys. Res. A 329, 337 (1993).

[15] Landen, O. L., Bell, P. M., McDonald, J. W., Park, H.-S., Weber, F., Moody, J. D., Lowry, M. E., Stewart, R. E., "Static and time-resolved 10-1000 keV x-ray imaging detector options for NIF," Rev. Sci. Instr. 75, 10 (2004).

[16] Boutboul, T., Akkerman, A., Gibrekhterman, A., Breskin, A., and Chechik, R., "An improved model for ultraviolet- and x-ray-induced electron emission from CsI,” J. Appl. Phys. 86, 10 (1999). 